\title{
Predicting internet addiction through executive functions; emphasizing on the components of inhibition, working memory and cognitive flexibility among students of Allameh Tabataba'i University
}

\author{
Sadegh Bakhtiary Javan', Noor Ali Farrokhi', Sajjad Bakhtiary Javan ${ }^{3}$, Rahman Sadeghi ${ }^{4}$ \\ 1-M.A. of Cognitive Psychology, Department of Psychology, Kurdistan University, Sanandaj, Iran. \\ 2- Associate Professor, Department of Assessment and Measurement, Allameh Tabataba'i Unversity, Tehran, Iran. \\ 3- M.A. Student of Assessment and Measurement, Department of Assessment and Measurement, Allameh \\ Tabataba'i University, Tehran, Iran (Corresponding Author). \\ E-mail: s.bakhtyarijavan@gmail.com \\ 4- M.A. Student of Management Social Work, Department of Management Social Work, Allameh Tabataba'i Uni- \\ versity, Tehran, Iran.
}

Received: $31 / 08 / 2020$

Accepted: $16 / 11 / 2020$

\begin{abstract}
Introduction: Internet addiction can be explained by various factors, including executive functions as multifunctional neuropsychological structures.

Aim: The purpose of this study is to predict internet addiction through executive functions among students of Allameh Tabataba'i University.

Method: The present study is a correlational study and its statistical population consists of students of Allameh Tabataba'i University who have studied in the second semester of the 2019 academic year. The statistical sample of the study included 206 Undergraduate Student who were selected by available sampling in this study. In order to measure Internet addiction, the Young Internet Addiction Questionnaire was used and to evaluate the executive functions Go/No Go Task, N-Back Task and Wisconsin Card Classification Task (WCST) were used. Correlation and regression analysis were used to analyze the data. Data were analyzed using SPSS 25 statistical software.
\end{abstract}

Results: The results of the analyzed data show that there was no relationship between working memory components ( $\mathrm{N}$-Back Test Series $\mathrm{n} 2)$ and Internet addiction $(\mathrm{P}<0.05)$. However, there is a significant negative relationship between internet addiction (first-series N-BACK), working memory and disinhibition and a significant positive relationship between internet addiction and cognitive flexibility. $(\mathrm{P}<0.05)$

Conclusion: The results of this study showed that executive functions can predict internet addiction in students. Executive functions can also be considered as one of the contributing factors to the persistence of Internet addiction.

Keywords: Addiction psychiatry, Executive function, Working memory, Flexibility

How to cite this article : Bakhtiary Javan S, Farrokhi NA, Bakhtiary Javan S, Sadeghi R. Predicting internet addiction through executive functions; emphasizing on the components of inhibition, working memory and cognitive flexibility among students of Allameh Tabataba'i University. Shenakht Journal of Psychology and Psychiatry. 2020; 7 (5): 80-91 .URL: http://shenakht.muk.ac.ir/article-1-969-en.pdf

Copyright ( 2018 the Author (s). Published by Kurdistan University of Medical Sciences. This is an open access article distributed under the terms of the Creative Commons Attribution-Non Commercial License 4.0 (CCBY-NC), where it is permissible to download, share, remix, transform, and buildup the work provided it is properly cited. The work cannot be used commercially without permission from the journal. 


\title{
بيشبينى اعتياد اينتر نتى از طريق كاركردهاى اجرايى؛ با تأكيد بر مؤلفههاى عدم بازدارى، حافظه كارى و انعطافيذيرى شناختى در ميان دانشجويان دانشكاه علامه طباطبائى
}

\author{
صادق بختيارى جوان'، نورعلى فرخى '، سجاد بختيارى جوان'، رحمان صادقىع \\ ا.كارشناس ارشد روانشناسى شناختى، گروه روانشناسى، دانشگاه كردستان، سنندج، ايران. \\ r. دانشيار، گروه سنجش و اندازگيرى، دانشگاه علامه طباطبائى، تهران، ايران. \\ r. دانشجوى كارشناسى ارشد سنجش و انداز گيرى، گروه سنجش و انداز گيرى، دانشخاه علامه طباطبائى، تهران، ايران (مولف مسئول). \\ ايميل: s.bakhtyarijavan@gmail.com \\ F. دانشجوى كارشناسى ارشد مديريت خدمات اجتماعى، گروه مديريت خدمات اجتماعى، دانشكاه علامه طباطبائى، تهران، ايران.
}

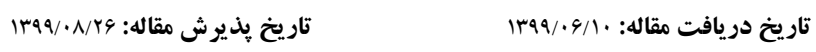

جكيuه

مقلمهه: اعتياد به اينترنت به وسيله عوامل مختلفى قابل تبيناند، در اين ميان مىتوان به كاركردهاى اجرايى به عنوان ساختارهاى جند منظوره عصبى -روانشناختى اشاره كرد.

هدف: اين ئزوهش به منظور ييشبينى اعتياد به اينترنت از طريق كاركردهاى اجرايى در ميان دانشجويان دانشخاه علامه طباطبائى صورت كرفت.

روش: يزوهش حاضر از نوع همبستخى و جامعه آمارى آن دانشجويان دانشگاه علامه طباطبائى بودند كه در نيمسال دوم سال تحصيلى 1M إl در اين يثوهش انتخاب شدند. به منظور سنجش اعتياد به اينترنت از يرسشنامه اعتياد به اينترنت يانگك و جهت ارزيابى كاركردهاى اجرايى از تكاليف برو/ نرو، ان بكك و كارتهاى ويسكانسين استفاده شد. جهت تجزيه و تحليل دادهها از همبستگى و تحليل ركرسيون استفاده شد. دادهها با استفاده از نرم افزار آمارى ها SPSS مورد تجزيه و تحليل قرار كرفتند.

يافتها: نتايج تحليل دادهها نشان مىدهد كه بين مؤلفهاى حافظه كارى (سرى دوم ان بكك) و اعتياد اينترنتى رابطه وجود ندارد (ه •/P>) در مقابل بين اعتياد اينترنتى و كاركردهاى حافظه كارى (ان بك سرى اول)، كنترل مهارى رابطه منفى معنادارى و انعطاف يذ يرى شناختى رابطه مثبت و معنادارى وجود دارد (ه •/ P (P).

نتيجه كيرى: نتايج اين يزٔوهش نشان داد كه كاركرد اجرايى مىتواند اعتياد به اينترنت را در دانشجويان بيشبينى كند. همجنين كار كردهاى اجرايى را مى توان به عنوان يكى از عو امل زمينه ساز و تداوم بخش در اعتياد به اينترنت دانست. كليدوازهها: اعتياد به اينترنت، كاركرد اجرايى، حافظه كارى، انعطافيذيرى 
از اعتبار تشخيص آن يشتيبانى مى كند (كو، ين، ين، جن

اختلال اعتياد به اينترنت'، به عنوان يك نخگرانى شايع در مفهوم اعتياد به اينترنت ريشه در اعتياد رفتارى دارد كه داراى الكوهاى رفتارى مشابه و علل بيولوزيكى، اعتياد به مواد است. در سالهاى اخير، اعتياد رفتارى را با توجه به همان معيار اعتياد به مواد در نظر مى گرفتند: تحمل، تركى، عدم كاهش يا ترك و اختلال در زندكى روزمره؛ اما مطالعات عصبى جديد اعتياد رفتارى ارتباطى را در بين تغييرات ساختار مغز و كار كردهاى مربوط به عملكرد مغز را در رابطه با ياداش، هيجانات، كاركرد اجرايى، توجه، تصميم گيرى و كنترل شناختى نشان مىدهند (يانگك بان،

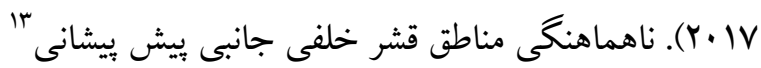
و قشر ييش بيشانى "l در اين افراد منجر به اختلال كاركرد شناختى، تصميم گيرى نادرست و افكار غير انعطافيذير مىشود. قشر ييش بيشانى با كرايش اعتياد به اينترنت

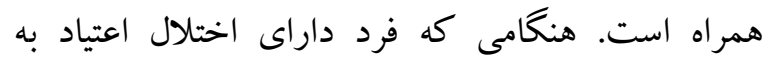
اينترنت سيكنال همراه با نوع اعتياد خود را نشان مىدهد، همرها، افزايش فعاليت در قشر بيش ويشانى ديده مىشود. قشر بيش بيشانى همجنين نقش مهمى را در تكاليف تصميمكيرى بر عهله دارد. افراد مبتلا به اعتياد سريعاً به سيخنالهاى مرتبط با اعتياد خود بِاسخ مىدهند. قشر بيش بيشانى در نوجوانان هنوز به اندازه كافى بالغ نشده است؛ بنابر اين اعتياد به اينترنت كه در اين گروه سنى بيشتر ديده مى شود، روى فر آيندهاى تحول و بلوغ ساختارهاى مغز تأثير

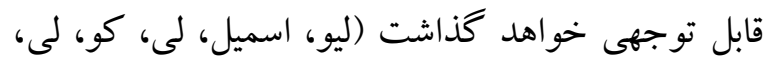

\footnotetext{
${ }^{11}$ - Ko, Yen, Yen, Chen \& Chen

${ }^{12}$ - Yung

13- Dorsolateral Prefrontal Cortex (DLPFC)

${ }^{14}$ - Prefrontal Cortex (PFC)
}

\footnotetext{
${ }^{1}$ - Internet Addiction Disorder (IAD)

- Spada

3 - Brand, Young \& Laier

4- Jain, Anand, Prabhu, Thomas, Bhat, Prathyusha \& Cherian

5- Gedam, Shivji, Goyal, Modi \& Ghosh

6 - Diagnostic And Statistical Manual Of Mental Disorders (DSM5)

7- Petry, Rehbein, Gentile, Lemmens, Rumpf, Mößle \& Auriacombe

${ }^{8}$ - Kaplan

9- Babakr, Majeed, Mohamedamin \& Kakamad

${ }^{10}$ - Durkee, Kaess, Carli, Parzer, Wasserman, Floderus \& Brunner
} 
اينترنتى رفتارهاى اعتيادى مشابه به ديخر اعتيادها مانند

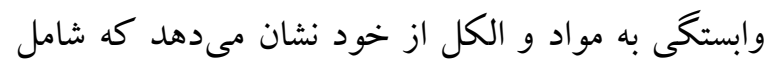
نقايصى مشخصى در حافظه كارى آنها است. حافظه كارى به عنوان يكى از كاركردهاى اجرايى مرتبه بالاتر،

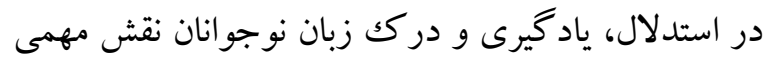

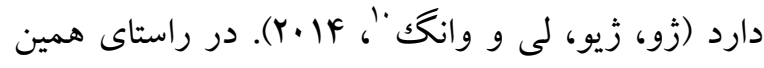
يثوهش تحقيقات حاصل از نقشهبردارى مغزى نشان مىدهد كه محركهاى مربوط به اينترنت با برخى از

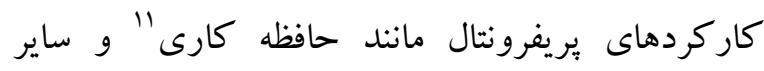
كاركردهاى اجرايى تداخل دارند (برند و همكاران،

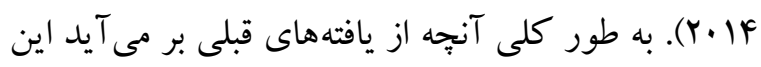

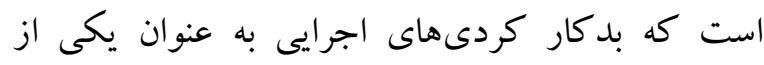
بازنمودهاى نقايص مغزى در افراد داراى اعتياد به اينترنت ديده مىشود. دسترسى آسان به اينترنت و فراوانى افراد مبتلا به اين اختلال كه نقايص زيرساختى شناختى مشخصى را به نمايش مى گذارند اهميت اين حوزه از بثزوهش را روز به روز بررنگك تر مىسازد. همجينين تأكيد بيشتر اين ئزوهش بر مؤلفه عدم بازدارى (به عنوان يكى از كاركردهاى اجرايى كه رهايى اين افراد از سيكل معيوب اعتياد به اينترنت را مشكلتر مىسازد)، حافظه كارى (كه به عنوان يكى از كاركردهاى اجرايى دركير در اين افراد مىتواند مشكلات مشخصى را در حوزه شغلى و تحصيلى براى آنها يديد آورد) و انعطاف يذيرى شناختى (به عنوان توانايى تغيير در تفكر و عمل براى يردازش درك و وِاسخگ افراد) در راستاى ياسخكويى به اين سؤال است كه آيا كاركردهاى اجرايى مىتوانند به طور معنادارى اعتياد به

$$
\text { اينترنت را بيشبينى كنند؟ ارج }
$$

${ }^{10}$ - Zhou, Zhu, Li \& Wang

${ }^{11}$ - Working Memory
كائو و زو'، سا.بr؛ سان، يينگك، سيتوهول، خوئمى، يا

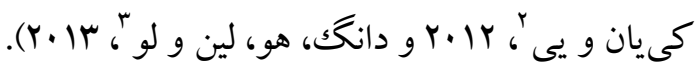
در همين راستا ديخر مطالعات نشان مىدهد افر اد مبتلا به وله اعتياد اينترنتى نقايص مشخصى در كاركردهاى اجرايى و حساسيتهايى نسبت به سيستم پِاداش و تنبيه دارند

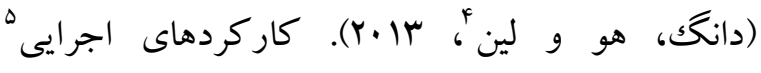

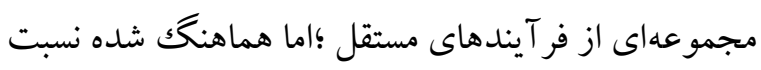

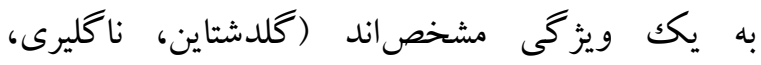

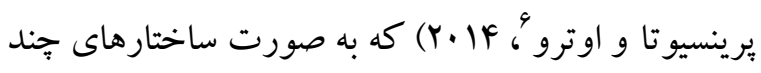
جند منظوره عصبى- روانشناختى فرض مىشوند و و توسط شبكهاى عصبى گسترده در مغز انسان يشتيبانى

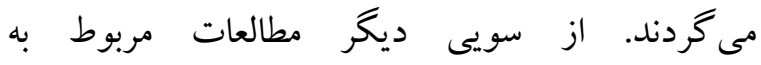
تصويربردارى عصبى نشان مىدهد كه افراد مبتلا به اعتياد اينترنتى نقايص مشخصى در كار كردهاى اجر ايى از جمله

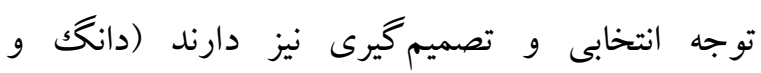

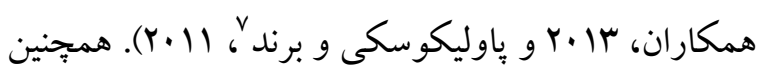
همجنين مىتوان بيان داشت كه نتايج مطالعات عصب روانشناسى كه نقش قابل توجهى را در بررسى اثر اعتياد اينترنتى بر كاركردهاى شناختى دارند حاكى از آن است؛ كه اعتياد اينترنتى يكك اختلال ذهنى است و افراد مبتلا به

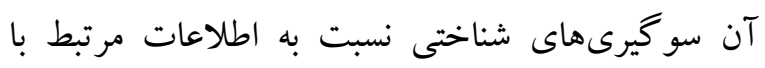
بازىهاى اينترنتى و مهارتهاى كاركرد اجرايى ضعيف دارند كه مىتوان به انعطافيذيرى شناختى و عدم

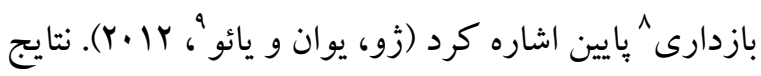
نتايج مطالعات ديخر نشان مىدهد كه افراد مبتلا به اعتياد

\footnotetext{
1. Liu, Esmail, Li, Kou, Li, Gao \& Zhou

2- Sun, Ying, Seetohul, Xuemei, Ya, Qian \& Ye

3 - Dong, $\mathrm{Hu}$, Lin \& Lu

4- Dong, Hu \& Lin

5 - Executive Function

${ }^{6}$ - Goldstein, Naglieri, Princiotta \& Otero

7- Pawlikowski \& Brand

${ }^{8}$ - Disinhibition

${ }^{9}$ - Zhou, Yuan \& Yao
} 
درجه ليكرت مشخص سازد. دامنه نمرات اين آزمون از •

تا ..1 است كه نمرات بالاتر نشان دهندهى اعتياد به

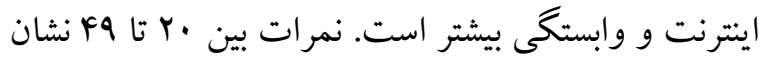
دهنده كاربر معمولى اينترنت، نمر هى •ه تا VA نشان دهنده

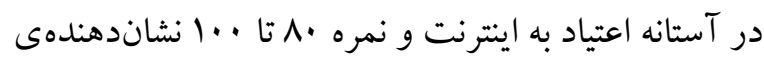
اعتياد به اينترنت است. به منظور بررسى ويزگىهاى

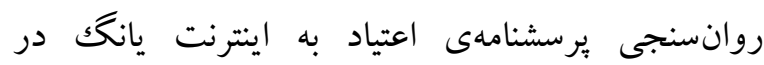
مطالعات خارجى آلفاى كرونباخ اين مقياس را •٪ •.

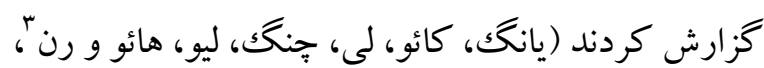

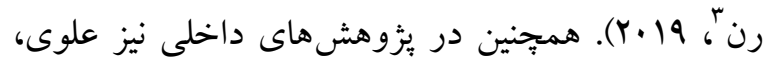
اسلامى، مراثى، نجفى، جنتى فرد و رضايور (INA9) ضريب آلفاى كرونباخ را براى اين مقياس را ر MA/. كزارش كردهاند. ضريب بايايى در اين بثزوهش نيز برابر با س// • به دست آمد. تكليف برو-نروء: اين تكليف كه نسخه اصلى و اوليه آن توسط هافمنه در سال 1911 طراحى شده است. به طور كلى جهت ارزيابى بازدارى بِاسخ به كار مىرود. بازدارى

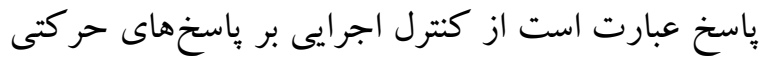
از ييش آماده، مطابق با تغيير درخواست موقعيتى. در تكليف برو - نرو، آزمودنى در يكك موقعيت (مرحله برو و

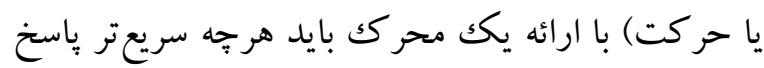
همخوان با محر كك را ارائه دهد. در موقعيت ديخر (مرحله نرو يا مهار حركت) يس از ارائه محرك نخست محر كs

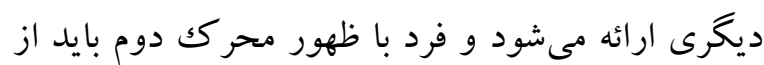
״ياسخ دادن خوددارى نمايد. توانايى فرد در مهار پِاسخ خود در موقعيت دوم، شاخصى از كنترل مهارى او است. نمره فرد در اين تكليف تعداد ياسخهاى درست و و نادرست در هر موقعيت است. همجنين ميانگين زمان

3 - Yang, Cao, Li, Cheng, Liu, Hao \& Ren

${ }^{4}$ - Go/No-Go Task

5 - Hoffman
اين يثزوهش از نوع همبستخى و جامعه آمارى آن دانشجويان دانشگاه علامه طباطبائى بودند كه در نيمسال

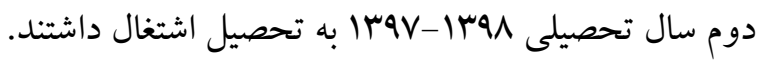

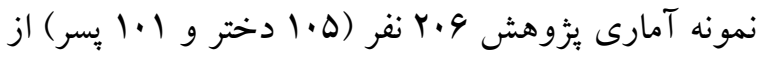
دانشجويانى بودند كه به روش نمونه گيرى در دسترس انتخاب شدند. يس از توزيع يرسشنامه و ارائه توضيحات لازم در مورد تكاليف شناختى، IYF IVI دختر و IVF

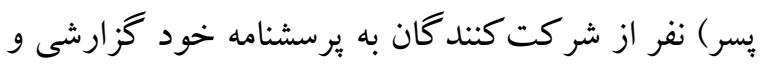

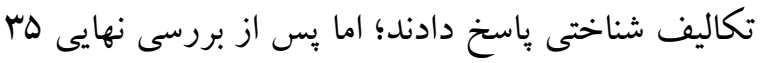
يرسشنامه و تكليف كه ناقص ارزيابى شدند، حذف و تحليل دادههاى آمارى تنها بر اساس Y.9.9 شركت كننده انجام شد. ملاككهاى ورود عبارتاند: دانشجوى دانشگاه علامه طباطبائى بودن، حداقل سن 11 تا سM سال و حداقل ميزان خواب (4 ساعت) در شبانهروز كذشته براى انجام تكاليف شناختى. ملاككهاى خروج شامل: سوءمصرف مواد، مصرف دارو، بيمارىهاى يزشكى و علائم سايكوتيك يا مانيا. جهت تجزيه و تحليل دادهها از آزمون كالمو گراف اسميرنوف (براى تعيين نرمال بودن دادهها)، همبستخى و تحليل رگر سيون استفاده شد. دادهها با استفاده از نرم افزار آمارى SpSS مورد تجزيه و تحليل قرار گر فتند.

ابزار برسشنامه اعتياد به /ينترنت يانتك ': اين برسشنامه در سال

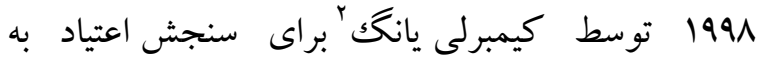

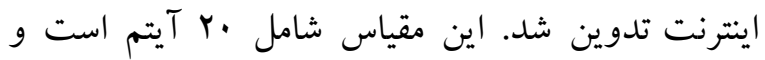
شركت كننده بايد بِاسخهاى خود را بر اساس طيف ينج

1- Young Internet Addiction Test ${ }^{2}$ - Young $\mathrm{K}$ 
ضريب بايايى اين تكليف در بزوهشهاى خارجى براى

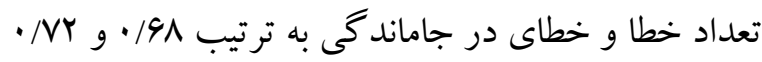

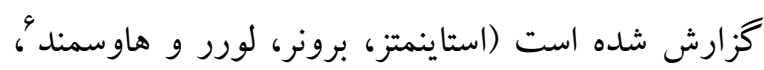

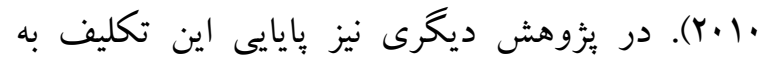
روش باز آزمايى با فاصله ·ل روز \$^/· به دست آمده

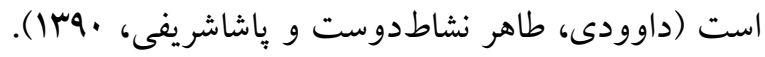
ضريب بايايى در اين يُوهش برابر با اN/· به دست آمد. در اين بزّوهش از نسخه كامبيوترى تكليف استفاده شده كه از اعتبار بين المللى برخوردار است. تكليف انبكك! ب تكليف ان بك ابتدا توسط كرجنر (1901) ساخته شد. اين تكليف يكى از بر كاربردترين ابزارها براى سنجش حافظه كارى است. در اين ابزار تعدادى محركك به صورت سرى بر روى صفحه نمايش بر برى با سرعت . . r ميلىثانيه ظاهر مىشوند. شركت كننده بايد

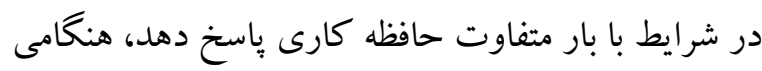
كه يككبار قبل دستورالعمل مدنظر باشد، يعنى شرايط با

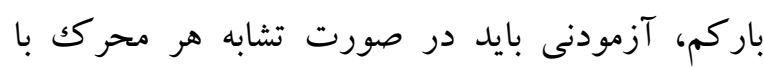
محركك قبل كليد را فشار دهد و زمانى كه دو بار قبل دستورالعمل مدنظر باشد، يعنى شرايط با اضافه بار زياد، آزمودنى بايد در صورت تشابه محركك با دو محرك قبل كليد را فشار دهد و همجينين مرتبههاى بالاتر هم به همين منوال است. در اين تكليف نمره پياسخهاى درست و

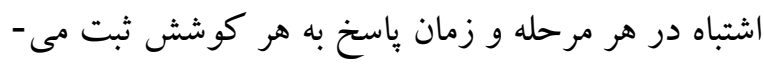

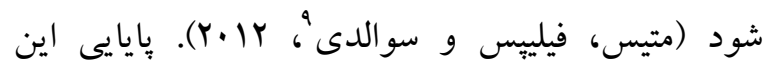
تكليف در مطالعات خارجى را اشميدك، لوودن و

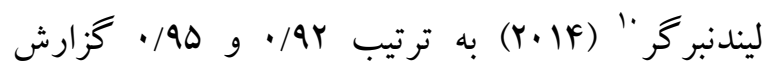
كردهاند. همجينين در مطالعات داخلى نيز اعتبار اين

${ }^{6}$ - Steinmetz, Brunner, Loarer \& Houssemand

${ }^{7}$ - N-Back Task

${ }^{8}$ - Kirchner

9 - Matthies, Philipsen \& Svaldi

${ }^{10}$ - Schmiedek, Lövdén \& Lindenberger
ياسخها نيز ثبت مىشود. ضرايب آلفاى كرونباخ بهدست آمده براى اين تكليف در يكك مطالعه خارجى به

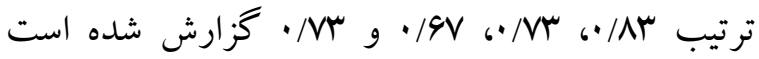

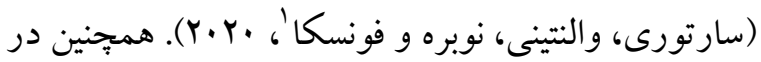

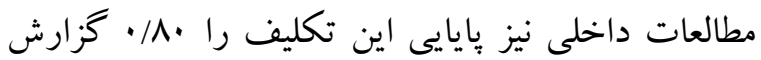
كردهاند (صفاريزدى و نجاتى، اهبا). ضريب يايايى در اين يثزوهش برابر با V9/• به دست آمد. در اين يزوهش از نسخه كامييوترى تكليف r استفاده شده كه از اعتبار بين المللى برخوردار است.

تكليف دستهبندى كارتهاى ويسكانسين"! تكليف دسته -

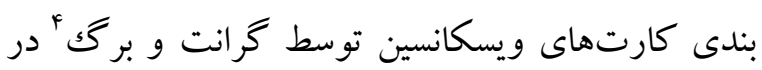
سال l941 براى اولين بار ساخته شد. اين تكليف به منظور سنجش انعطاف يذيرى شناختى به كار مىرود. نسخه كارتى اين تكليف از Fانوع كارت داراى اشكال مختلف

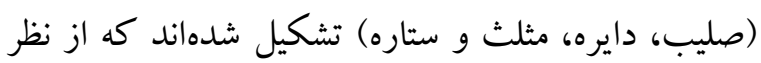
رنگگ، شكل و تعداد با هم متفاوت هستند. هر كارت داراى يكى از رنگكهاى آبى، قرمز، زرد و سبز است و بر روى هر كارتى جهار شكل (دايره، مثلث، صليب و و ستاره) قرار كرفته است. تعداد اشكال روى يك كرى كارت نيز از يكك تا جهار فرق مى كند، بهاينترتيب كه هيج كدام از كارت ها شبيه هم نيستند. نمره فرد در اين آزمون تعداد دسته كارتهاى دهتايى است كه به صورت موفقيت آميز دستهبندى كرده است. همجِين اكر فرد علىرغم تغيير

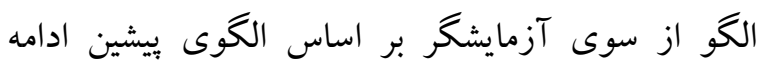
دهد، مرتكب خطاى در جاماندگى مىشود. خطاى در جاماندگى به طور كلى تكرار يكك باسخ بيش آموخته در برابر الكوى جديد است (كفادر و اورهانه، 19.ب).

\footnotetext{
1- Sartori, Valentini, Nobre \& Fonseca

2 - Psychology Experiment Building Language (PEBL)

3 - Wisconsin Card Sorting Inspired Task

4. Grant \& Berg

5 - Kafadar \& Orhan
} 


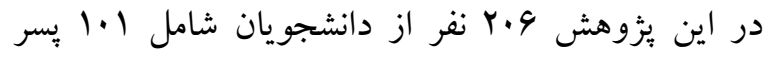

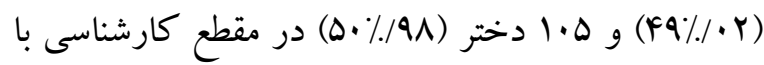
ميانگين سنى r/Y I Y Y سال مورد مطالعه قرار گرفتند. شاخص توصيفى مربوط به اعتياد اينترنتى، عدم بازدارى، حافظه كارى و انعطاف يذيرى شناختى در جدول 1

$$
\text { كزارش شده است. }
$$

آزمون به عنوان يكك آزمون معتبر بيان شده است (نجاتى،

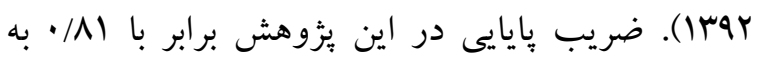
دست آمد. در اين يثوهش از توالى حروف و اشكال نسخه كامييوترى تكليف استفاده شده كه از اعتبار بين المللى برخوردار است.

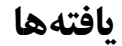

\begin{tabular}{|c|c|c|}
\hline \multicolumn{3}{|c|}{ جدول ا شاخصهاى توصيفى در دانشجويان كروه نمونه } \\
\hline انحر اف معيار & ميانكين & شاخصهاى آمارى متغيرها \\
\hline$\Delta V / T$ & $99 / 4 \wedge$ & اعتياد به اينترنت إنت \\
\hline $90 / \mathrm{V}$ & $\cdot V / r)$ & انعطاف يذيرى شناختى \\
\hline $\mathrm{Kr} / \mathrm{G}$ & $|Y| / \Lambda \Delta$ & حافظه كارى (ان بك سرى اول) \\
\hline$\wedge 9 / \Delta$ & $\Lambda I / A F$ & حافظه كارى (ان بك سرى دوم) \\
\hline$r \cdot /$. & $99 / r 9 V$ & 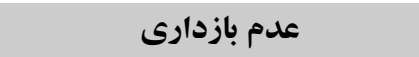 \\
\hline
\end{tabular}

. نوع نرمالاند ( •

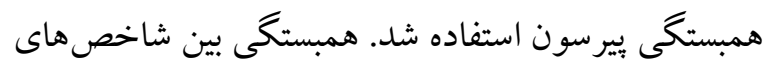
تكاليف و نمره اعتياد به اينترنت در جدول شماره كزارش شده است.
نتايج جدول شماره ا نشان داد كه متغير اعتياد به اينترنت دارى ميانگين و و انحراف معيار

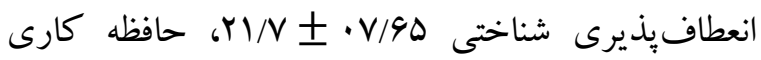

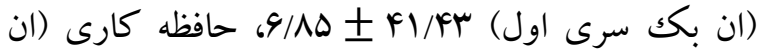
بك سرى دوم) NF/D

\begin{tabular}{|c|c|c|c|}
\hline سطح معنادارى & همبستى & شاخصها & تكاليف \\
\hline$\cdots 1 /$ & $r Y / \cdot$ & پِاسخ نادرست & كارتهاى ويسكانسين \\
\hline$\cdots 1 /$ & $\Delta 1 / \cdot-$ & سرى اول & انبك \\
\hline $9 /$. & $-. \Delta 9 /$ & سرى دوم & \\
\hline$\cdots 1 / \%$ & $-\$ q /$. & پاسخ درست & برو -نزو \\
\hline
\end{tabular}

نتايج جدول شماره Y نشان مىدهد كه اعتياد به اينترنت نادرست تكليف دستهبندى كارتهاى ويسكانسين

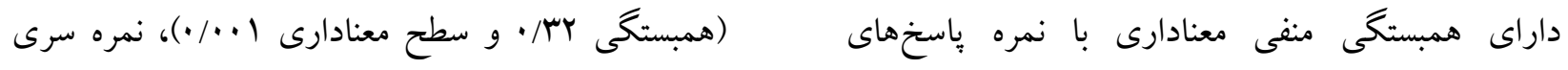




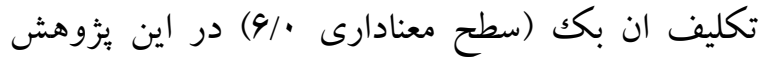

اول تكليف ان بكك (همبستخى 101/•- و سطح معنادارى يافت نشد. تحليل رگر سيون خطى بيشبينى اعتياد اينترنتى

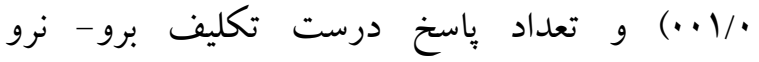
از طريق نمره سرى اول تكليف انبك در جدول شماره

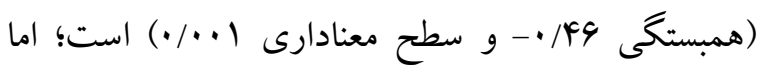
كزارش شده است. رابطه معنادارى بين اعتياد به اينترنت و نمرات سرى دوم

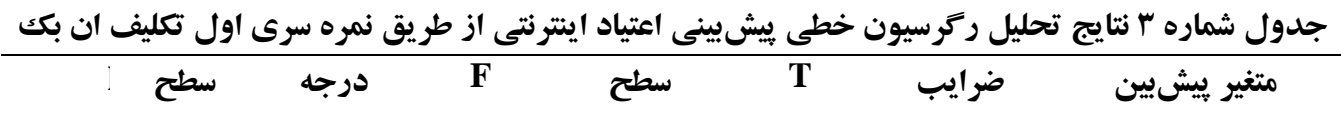

\begin{tabular}{|c|c|c|c|c|c|c|c|}
\hline & معنادارى & آزادى & & معنادارى & & استاندارد & \\
\hline \multirow[t]{2}{*}{ re/. } & $\cdots 1 /$ & 1 & $19 / \mathrm{VI}$ & $\cdot / \cdot 1$ & $9 Y / I Y$ & - & مقدار ثابت \\
\hline & & & & $\cdots 1 /$ & $-F V / \Lambda$ & $-\Delta 1 /$. & سرى اول \\
\hline
\end{tabular}

آزادى | و سطح معنادارى ·/1 ·.) بيشبينى مى كند. نتايج تحليل رگرسيون خطى بيشبينى اعتياد اينترنى از طريق نمره كل باسخهاى درست تكليف برو- نرو در جدول شماره F كزارش شده است.
نتايج جدول شماره r نشان مىدهد كه در اين مدل شاخص نمره سرى اول تكليف انبكك اعتياد به اينترنت (T =-FV/A)

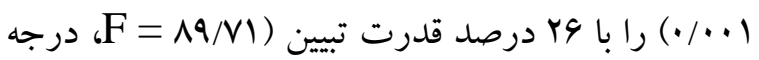

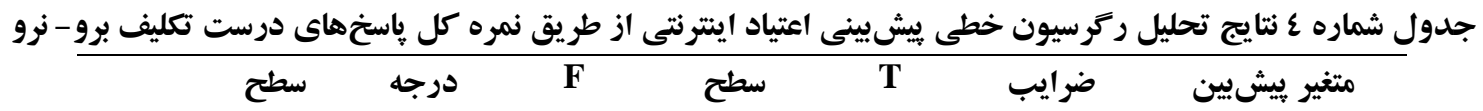
استاندارد

\begin{tabular}{|c|c|c|c|c|c|c|c|}
\hline \multirow[t]{2}{*}{$r \mid / \cdot$} & \multirow[t]{2}{*}{$. \cdot 1 /$} & \multirow[t]{2}{*}{1} & \multirow[t]{2}{*}{$s F / \Delta \Delta$} & $\cdots 1 /$ & $M F / q$ & - & مقدار ثابت \\
\hline & & & & $\cdots 1 /$ & $-G F / V$ & $-199 /$. & ياسخ درست \\
\hline
\end{tabular}

مى كند. نتايج تحليل ركرسيون خطى بيشبينى اعتياد اينترنى از طريق نمره كل بِاسخهاى درست تكليف دستهندى كارتهاى ويسكانسين در جدول شماره هـ

$$
\text { كزارش شده است. }
$$

نتايج جدول شماره f نشان مىدهد در اين مدل كه شاخص نمره ياسخهاى درست تكليف برو -نرو اعتياد به

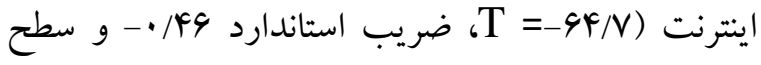

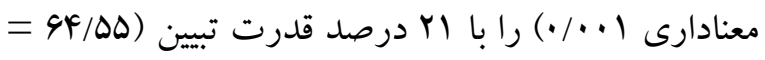
F

جدول ه شماره نتايج تحليل ركرسيون خطى ييشبينى اعتياد ايتترنتى از طريق نمره كل باسخهاى درست تكليف كارتهاى ويسكانسين

\begin{tabular}{|c|c|c|c|c|c|c|c|}
\hline & سعنادارى & آز آزه & $\mathbf{F}$ & سطنح & $\mathbf{T}$ & ضر ايب استاندارد & متغير بيشين \\
\hline \multirow[t]{2}{*}{$1 / \cdot$} & $\cdot 1 \cdots 1$ & 1 & YF/MF & $\cdot / \cdots 1$ & $\Lambda \Delta / \Lambda$ & - & مقلار ثابت \\
\hline & & & & $\cdot 1 \cdots 1$ & $F / 94$ & $\mathrm{rr} /$. & ياسخ نادرست \\
\hline
\end{tabular}


اين كار كرد شناختى رهايى فرد از اين سيكل معيوب را مشكلتر ساخته و باعث مىشود فرد ساعات بسيارى از وقت بيدارى خود را در وبكردىهاى، شبكهاى اجتماعى و بازىهاى اينترنتى بگذراند و به سختى مى تواند از اين فعاليتها دست بكشد. از بازئ طرفى ديخر

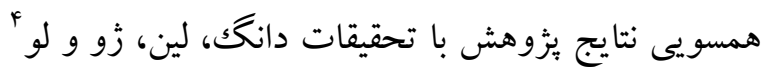

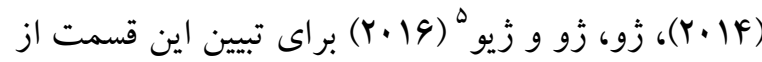
فرضيهى بُزوهش مبنى بر بيش بينى اعتياد به اينترنت از طريق انعطاف يذيرى شناختى را مى توان اين گونه بيان كرد كه انعطاف يذيرى شناختى، خود از ويز گیىهاى مهم براى سازش يافتن با شرايط است و مىتواند توضيح دهنده غلبه تمايل به سازش اين افراد به شرايط و كاستى هاى مربوط به سازش يافتن با شرايط متغير بيرونى آنها باشد. به علاوه همسويى نتايج اين يزوهش با نتايج

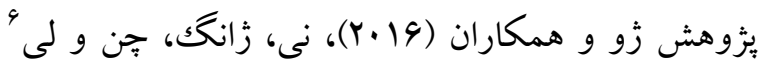
(Y.19) در راستاى تبيين اين فرضيه از بثزوهش كه مبنى بر بيشبينى اعتياد به اينترنت از طريق حافظه كارى است را مىتوان اين گونه بيان كرد كه حافظه كارى، مسئول نخهارى و يردازش بيامهاى جديد و از قبل ذخيره شده است. حافظه كارى يكك فرايند مهم بر ایى درك، استدلال،

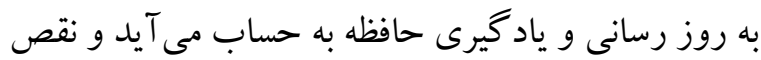
در اين كاركرد شناختى مىتواند بدكار كردهاى را در زمينه شغلى، اجتماعى و تحصيلى براى اين افراد بديد

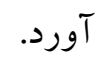

\section{نتيجه كيرى}

به طور كلى نتايج يثوهش نشان داد كه عدم بازدارى، حافظه كارى و انعطاف بذيرى شناختى به عنوان

${ }^{4}$ - Dong, Lin, Zhou \& Lu

5 - Zhou, zhou \& zhu

${ }^{6}$ - Nie, Zhang, Chen \& Li
نتايج جدول شماره ه نشان مىدهد در اين مدل شاخص نمره ياسخهاى نادرست تكليف كارتهاى ويسكانسين اعتياد به اينترنت (

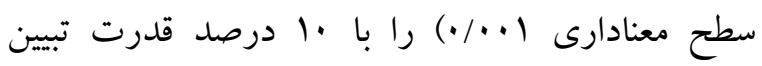

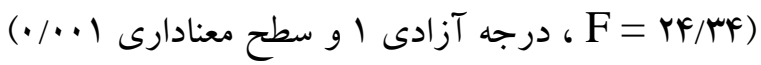

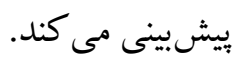
اين يثوهش با هدف بيشبينى اعتياد اينترنتى از طريق كاركردهاى اجرايى؛ با تأكيد بر مؤلفههاى عدم بازدارى، حافظه كارى و انعطاف يذيرى شناختى در ميان دانشجويان دانشگاه علامه طباطبائى انجام شد. نتايج بهدستآمده از اين تحليل نشان داد بين كاركردهاى اجرايى؛ حافظه كارى (شاخص سرى اول تكليف انبك)، عدم بازدارى (تكليف برو - نرو) و انعطاف يذيرى شناختى (تكليف دسته بندى كارتهاى ويسكانسين) با اعتياد اينترنتى رابطه وجود دارد. اين يافتها با نتايج بثوهش هاى

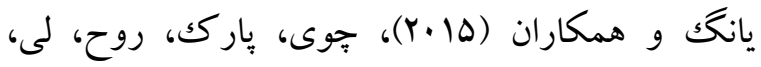

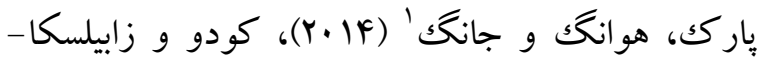

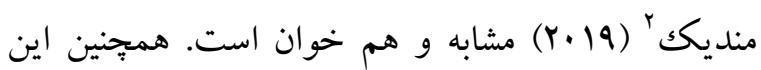

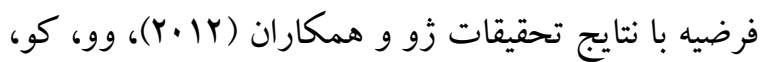

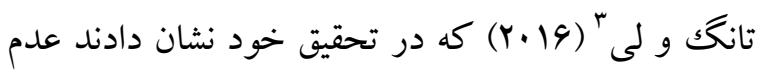
بازدارى با قدرت تبيين بالاترى نسبت به حافظه كارى و

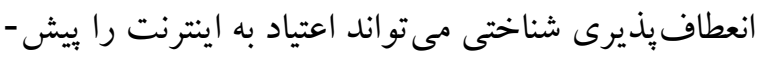
بينى كند، همسو است. در تبيين اين فرضيه مىتوان جنين اظهارنظر كرد كه عدم بازدارى در اين افراد مىتواند ناشى از رفتار وسواس گونهاى باشد كه فرد را دركير يكك سيكل معيوب از اين رفتار اعتيادى مى كند. نقص در

\footnotetext{
1- Choi, Park, Roh, Lee, Park, Hwang \& Jung

${ }^{2}$ - Cudo \& Zabielska-Mendyk

${ }^{3}$ - Wu, Ko, Tung \& Li
} 
مناطق ديكر كشور تكرار شود تا بتوان به ميزان درصد شيوع رو به رشد اين اختلال در جوامع مختلف كشور و نتايج دقيقتر دست يافت. همجنين بيشنهاد مى شود كه به منظور سنجش دقيقتر از ابزارهاى هنجاريابى شده مشخص كه توسط افراد متخصص فر آيند ساخت و اعتبار يابى آنها انجام شده باشد، استفاده شود.

\section{سياسگزارى}

از دانشجويان دانشگاه علامه طباطبائى تهران كه در اين يثزوشش ما را يارى نمودند، كمال تشكر و قدردانى را

داريم.

\section{References}

Alavi S, Eslami M, Merati M, Najafi M, Janatifard F, Rezapour H. (2010). The psychometric properties of Young internet addiction among students. Behav Sci, 4(3), 183-189. (In Persian)

Babakr ZH, Majeed K, Mohamedamin P, Kakamad K. (2019). Internet Addiction in Kurdistan University Students: Prevalence and Association with Self-Control. European Journal of Educational Research, 8(3), 867-873. doi: 10.12973/eu-jer.8.3.867 (In Persian)

Brand M, Young KS, Laier C. (2014). Prefrontal control and Internet addiction: a theoretical model and review of neuropsychological and neuroimaging findings. Frontiers in human neuroscience, 8 , 375. doi: 10.3389/fnhum.2014.00375

Choi JS, Park SM, Roh MS, Lee JY, Park CB, Hwang JY, Jung HY. (2014). Dysfunctional inhibitory control and impulsivity in Internet addiction. Psychiatry research, 215(2), 424-428. doi: org/10.1016/j.psychres.2013.12.001

Cudo A, Zabielska-Mendyk E. (2019). Cognitive functions in Internet addiction-a review. Psychiatr Pol, 53(1), 61-79. doi: org/10.12740/PP/82194

Davoodi A, Taherneshatdust H, Pashasharifi H. (2011). The comparison of executive functions in pa
كاركردهاى اجرايى مىتوانند اعتياد به اينترنت را ييش بينى كنند. همجنين ارزيابىهاى عصبى - شناختى در اين مطالعه با استفاده از تكاليف شناختى، نقايص مشخصى در كاركردهاى شناختى در افراد مبتلا به اعتياد اينترنتى نشان مىدهد. اميد است كه اين ارزيابى عصبى شناختى بتوانند زمينه را براى تحقيقات كسترده، ساخت تكاليف شناختى و بستهاى درمانى كاربردى فراهم آورند تا بتوان آن را به منظور تشخيص، ارزيابى و بهبود نقايص شناختى اين افر اد با استفاده از رويكرد توانبخشى شناختى به كار برد. در اين بزّوهش نيز همانند ساير بززوهشهاى علمى ديخر مجموعهاى از موانع و محدوديتها وجود داشت. برخى

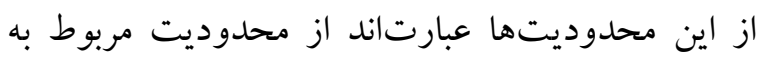
نمونه يُزوهش كه در اين بُزوهش فقط قشر دانشجويان بودند و انتار مىرود اين بثزوهش در ميان قشر غير دانشجويان نيز به صورت وسيعى انجام كيرد. محدوديت

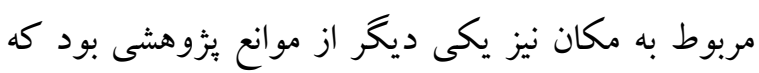

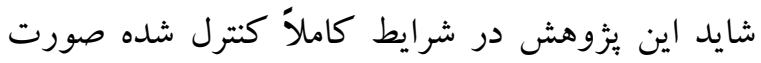

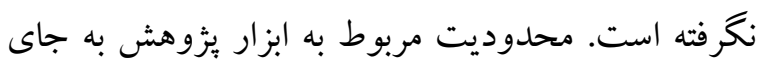
استفاده از مجموعه نرم افزار تكاليف شناختى PEBL كه در اين ئزوهش استفاده شد مىتوان از نرم افزار مناسبترى به منظور سنجش كاركردهاى اجرايى استفاده كرد. همجنين يزوهش حاضر جهت بيشبينى بد كاركردهاى اجرايى مى تواند زمينه ساز شناسايى مشكلات و نقايص شناختى در افراد داراى اختلال اعتياد به اينترنت باشد. انتظار مىرود كه تحقيقات بعدى نيز مدلهايى را مطرح سازند كه به بيشبينى مشكلات اين افراد كمكك نمايند. اين امر تنها در سايه بررسى وسيعتر مؤلفهاى شناختى تداوم بخش اين اختلال اعتيادى محقق خو اهد شد. انتظار مىرود اين مطالعه در جوامع غير از دانشجويان و ساير 
tients with schizophrenia, non psychotic major depression and normal individuals in Tehran. Arak Med Uni J, 14(4), 10-19. (In Persian)

Dong G, Hu Y, Lin X, Lu Q. (2013). What makes Internet addicts continue playing online even when faced by severe negative consequences? Possible explanations from an fMRI study. Biological psychology, 94(2), 282-289. doi: org/10.1016/j.biopsycho.2013.07.009

Dong G, Hu Y, Lin X. (2013). Reward/punishment sensitivities among internet addicts: implications for their addictive behaviors. Progress in Neuro-Psychopharmacology and Biological Psychiatry, 46, 139-145. doi: org/10.1016/j.pnpbp.2013.07.007

Dong G, Lin X, Zhou H, Lu Q. (2014). Cognitive flexibility in internet addicts: AMRI evidence from difficult-to-easy and easy-to-difficult switching situations. Addictive Behaviors, 39(3), 677683. doi: org/10.1016/j.addbeh.2013.11.028

Durkee T, Kaess M, Carli V, Parzer P, Wasserman C, Floderus B, Brunner R. (2012). Prevalence of pathological intemet use among adolescents in Europe: demographic and social factors. Addiction, 107(12), 2210-2222. doi: 10.1111/j.1360-0443.2012.03946.x

Gedam SR, Shivji IA, Goyal A, Modi L, Ghosh S. (2016). Comparison of internet addiction, pattern and psychopathology between medical and dental students. Asian journal of psychiatry, 22, 105-110. doi: org/10.1016/j.ajp.2016.06.007

Goldstein S, Naglieri JA, Princiotta D, Otero TM. (2014). Introduction: A history of executive functioning as a theoretical and clinical construct. In Handbook of executive functioning (pp. 3-12). Springer, New York, NY. doi: org/10.1007/978-1-4614-8106-5_1

Jain PA, Anand N, Prabhu S, Thomas C, Bhat A, Prathyusha PV, Cherian AV. (2018). Internet use patterns, internet addiction, and psychological distress among engineering university students: A study from India. Indian joumal of psychological medicine, 40(5), 458-467. doi: 10.4103/IJPSYM.IJPSYM_135_18
Kafadar H, Orhan IB. (2016). The Relationship between Wisconsin Card Sorting Test and Raven Standard Progressive Matrices: A Latent Variable Analysis. International Online Journal of Educational Sciences, 8(1), 48-56. doi: 10.15345/iojes.2016.01.005

Kaplan H. (2015). Kaplan \& Sadock's synopsis of psychiatry. Philadelphia: Wolter Kluwer.

Ko Ch, Yen JY, Yen CF, Chen CS, Chen CC. (2012). The association between Internet addiction and psychiatric disorder: a review of the literature.European Psychiatry, 27(1), 1-8. doi: org/10.1016/j.eurpsy.2010.04.011

Liu J, Esmail F, Li L, Kou Z, Li W, Gao X, Zhou S. (2013). Decreased frontal lobe function in people with Internet addiction disorder. Neural regeneration research, $8(34), \quad 3225$. doi: 10.3969/j.issn.1673-5374.2013.34.006

Matthies S, Philipsen A, Svaldi J. (2012). Risky decision making in adults with ADHD. Journal of behavior therapy and experimental psychiatry, 43(3), 938-946. doi: org/10.1016/j.jbtep.2012.02.002

Nejati V. (2013). Comelation of risky decision making with executive function of brain in adolescences. (In Persian)

Nie J, Zhang W, Chen J, Li W. (2016). Impaired inhibition and working memory in response to internet-related words among adolescents with internet addiction: A comparison with attention-deficit/hyperactivity disorder.Psychiatry research, 236, 28-34. doi: org/10.1016/j.psychres.2016.01.004

Pawlikowski M, Brand M. (2011). Excessive Internet gaming and decision making: do excessive World of Warcraft players have problems in decision making under risky conditions? Psychiatry research, 188(3), 428-433. doi: org/10.1016/j.psychres.2011.05.017

Petry NM, Rehbein F, Gentile DA, Lemmens JS, Rumpf HJ, Moble T, Auriacombe M. (2014). An intemational consensus for assessing internet gaming disorder using the new DSM-5 approach. Addiction, 109(9), 1399-1406. doi: org/10.1111/add.12457 
Safaryazdi Z, Nejati V. (2012). The comparison of impulsiveness and risky decision making of fat and thin people. Science magazine of medical science university of Qazvin, 16 (1), 58-64. (In Persian)

Sartori RF, Valentini NC, Nobre GC, Fonseca RP. (2020). motor and verbal inhibitory control: development and validity of the go/No-Go app test for children with development coordination disorder. Applied Neuropsychology: Child, 2, 1-10. doi: $10.1080 / 21622965.2020 .1726178$

Schmiedek F, Lovden M, Lindenberger U. (2014). A task is a task is a task: putting complex span, $\mathrm{n}$ back, and other working memory indicators in psychometric context. Frontiers in psychology, 5 , 1475. doi.org/10.3389/fpsyg.2014.01475

Spada MM. (2014). An overview of problematic Internet use. Addictive behaviors, 39(1), 3-6. doi: org/10.1016/j.addbeh.2013.09.007

Steinmetz JP, Brunner M, Loarer E, Houssemand C. (2010). Incomplete psychometric equivalence of scores obtained on the manual and the computer version of the Wisconsin Card Sorting Test?Psychological Assessment, 22(1), 199-202. doi: org/10.1037/a0017661

Sun Y, Ying H, Seetohul RM, Xuemei W, Ya Z, Qian L, Ye S. (2012). Brain fMRI study of crave induced by cue pictures in online game addicts (male adolescents). Behavioural brain research, 233(2), 563-576. doi: org/10.1016/j.bbr.2012.05.005

Wu JYW, Ko HC, Tung YY, Li CC. (2016). Internet use expectancy for tension reduction and disinhibition mediates the relationship between borderline personality disorder features and Internet addiction among college students-Oneyear follow-up. Computers in Human Behavior, 55, 851-855. doi: org/10.1016/j.chb.2015.09.047m

Yang G, Cao J, Li Y, Cheng P, Liu B, Hao Z, Ren Z (2019). Association between Intemet Addiction and the Risk of Musculoskeletal Pain among Chinese College Freshmen-A Cross-Sectional Study. Frontiers in psycholo-

$$
\begin{aligned}
& \text { gy, 10, } 1959 . \quad \text { doi } \\
& \text { :org/10.3389/fpsyg.2019.01959 }
\end{aligned}
$$

Young KS. (2017). Internet addiction in children and adolescents: risk factors, assessment, and treatment. Springer Publishing Company.

Yung K, Eickhoff E, Davis DL, Klam WP, Doan AP. (2015). Internet addiction disorder and problematic use of Google Glass ${ }^{\mathrm{TM}}$ in patient treated at a residential substance abuse treatment program. Addictive behaviors, 41, 58-60. doi: org/10.1016/j.addbeh.2014.09.024

Zhou Z, Yuan G, Yao J. (2012). Cognitive biases toward Intemet game-related pictures and executive deficits in individuals with an Internet game addiction. PloS one,7(11), 48. doi: org/10.1371/journal.pone.0048961

Zhou Z, Zhou H, Zhu H. (2016). Working memory, executive function and impulsivity in Internetaddictive disorders: a comparison with pathological gambling. Acta Neuropsychiatrica, 28(2), 92-100. doi: org/10.1017/neu.2015.54

Zhou Z, Zhu H, LiC, Wang J. (2014). Internet addictive individuals share impulsivity and executive dysfunction with alcohol-dependent patients. Frontiers in behavioral neuroscience, 8 , 288. doi: org/10.3389/fnbeh.2014.00288 